\title{
Brinquedo terapêutico no preparo da criança para punção venosa em pronto socorro*
}

\author{
Therapeutic play to prepare children for intravenous placement in the emergency room
}

Juego terapéutico en la preparación del niño para la punción venosa en un servicio de emergencia

\author{
Giuliana Medeiros ${ }^{1}$, Shimeny Matsumoto ${ }^{2}$, Circéa Amalia Ribeiro ${ }^{3}$, Regina \\ Issuzu Hirooka de Borba ${ }^{4}$
}

\begin{abstract}
RESUMO
Objetivos: Preparar a criança pré-escolar para punção venosa por meio do Brinquedo Terapêutico Instrucional (BTI) e conhecer a percepção dos familiares quanto a esse preparo. Métodos: Estudo descritivo qualitativo realizado na unidade de emergência de um hospital universitário da cidade de São Paulo. Os sujeitos foram cinco crianças pré-escolares e seus familiares. Resultados: O BTI permitiu à criança saber o que deve esperar e como pode participar da punção venosa; compreender sua finalidade; envolver-se na situação; manipular o material e estabelecer relação de confiança com o profissional; os familiares reconheceram seu benefício no preparo da criança e proporcionaram a ela importante fonte de apoio e proteção. Considerações Finais: A utilização do BTI deve integrar o cuidado de enfermagem prestado à criança nas unidades de emergência, assegurando uma assistência humanizada e de qualidade.
\end{abstract}

Descritores: Jogos e brinquedos; Serviços médicos de emergência; Enfermagem pediátrica; Criança

\begin{abstract}
Objectives: To examine the usefulness of therapeutic instructional toy (TIT) in preparing preschool children for intravenous placement and to describe family member's perception of the children preparation. Methods: Descriptive qualitative study with 5 children and their family receiving care in an emergency room of a university teaching hospital in São Paulo city. Results: The use of TIT was a useful strategy to teach children what to expect and how to participate and collaborate during intravenous placement procedure, how to understand its objective, and how to get involved during the procedure. Children had the opportunity to manipulate the materials and establish trust in the health care provider. Family members recognized the benefits of therapeutic play and provided support and protection to the children during the intravenous placement procedure. Final considerations: The use of TIT to prepare children for intravenous placement must be an integral part of nursing practice in emergency rooms to guarantee quality and humanized nursing care to children.
\end{abstract}

Keyword: Play and playthings; Emergency medical services; Pediatric nursing; Child

\section{RESUMEN}

Objetivos: Preparar al niño pre-escolar para la punción venosa por medio del Juego Terapéutico Instruccional (JTI) y conocer la percepción de los familiares en cuanto a esa preparación. Métodos: Estudio descriptivo cualitativo realizado en el servicio de emergencia de un hospital universitario de la ciudad de Sao Paulo. Los sujetos fueron cinco niños pre-escolares y sus familiares. Resultados: El JTI permitió al niño saber lo que debe esperar y cómo puede participar de la punción venosa; comprender su finalidad; involucrarse en la situación; manipular el material y establecer relación de confianza con el profesional; los familiares reconocieron su benefício en la preparación del niño proporcionándole una importante fuente de apoyo y protección. Consideraciones Finales: La utilización del JTI debe integrar el cuidado de enfermería prestado al niño en los servicios de emergencia, asegurando una asistencia humanizada y de calidad.

Descriptores: Juego e implementos de juego; Servicios médicos de urgencia; Enferméria pediátrica; Niño

\footnotetext{
* Trabalho de Conclusão do Curso de graduação em Enfermagem apresentado na Universidade Federal de São Paulo - UNIFESP - São Paulo (SP), Brasil, em 2007, vinculado ao Grupo de Estudos do Brinquedo-GEBrinq - São Paulo (SP), Brasil.

${ }^{1}$ Especialista em Terapia Intensiva. Enfermeira Trainee do Hospital e Maternidade São Luiz - São Paulo (SP), Brasil.

${ }^{2}$ Especialista em Clinica Cirúrgica. Enfermeira do Hospital Santa Cruz - São Paulo (SP), Brasil.

${ }^{3}$ Professora Associada do Departamento de Enfermagem da Universidade Federal de São Paulo - UNIFESP - São Paulo (SP), Brasil

${ }^{4}$ Professora Adjunto do Departamento de Enfermagem da Universidade Federal de São Paulo - UNIFESP - São Paulo (SP), Brasil.
} 


\section{INTRODUÇÃO}

Durante um atendimento de emergência, a criança é comumente submetida a procedimentos invasivos, como a punção venosa. Vários estudos apontam que este é um momento estressante, por ser desconhecido, intrusivo e doloroso, sendo retratado como uma experiência desagradável, amedrontadora e traumática sobretudo para a criança pré-escolar, podendo aumentar significativamente o seu medo e a ansiedade, expressos por meio do choro, da raiva e agressões peculiares à idade ${ }^{(1-4)}$, ocorrência vivenciada pelos pais com muito sofrimento e angústia ${ }^{(5-7)}$. Desta forma, além da execução da técnica, é imprescindível que tanto a criança, como sua família sejam preparadas para esses procedimentos.

Se a punção venosa for realizada sem um preparo prévio, a criança, especialmente, em idade pré-escolar, pode ter prejuízos em seu desenvolvimento ${ }^{(2,4)}$ devido ao fato de não ter, ainda, estrutura cognitiva suficiente para compreender a experiência pela qual passa ${ }^{(1-3)}$. A característica egocêntrica da criança dessa faixa etária dificulta a aceitação de um procedimento doloroso, como um tratamento necessário, podendo interpretá-lo como um castigo ou punição, além de ser naturalmente vulnerável às ameaças de lesão corporal. Portanto, os procedimentos intrusivos, como a punção venosa, tornam-se ameaçadores, um ato hostil e mutilador, uma vez que a integridade da pele é rompida e elas temem que o conteúdo intracorpóreo se perca no ambiente ${ }^{(3)}$.

$\mathrm{Na}$ tentativa de amenizar o sofrimento e os traumas causados pelos procedimentos intrusivos, pesquisas relativas ao preparo da criança vêm sendo desenvolvidas, utilizando o Brinquedo Terapêutico Instrucional (BTI), como uma intervenção eficaz que permite à criança: saber o que deve esperar e como deve participar durante o procedimento; compreender a finalidade do procedimento; envolver-se na situação ao invés de ser tratada como objeto passivo; manipular material previamente e posteriormente estabelecer relação de confiança com o adulto e o profissional ${ }^{(2,8-10)}$.

Estudos constatam que quando as crianças são preparadas para punção venosa, tornam-se mais cooperativas, expressam melhor seus sentimentos de medo e ansiedade, demonstram compreender a necessidade do procedimento, diminuem as reações de tensão e passam a se relacionar melhor com outras crianças e a equipe de enfermagem ${ }^{(2,4,7,9)}$.

Apesar dos estudos supracitados demonstrarem os benefícios decorrentes da utilização do BTI, essa prática é pouco empregada no processo de prestação de assistência à criança nos serviços de saúde, havendo necessidade das crianças serem contidas até por três a quatro adultos, sob protestos, como choro, grito e recusa para realização do procedimento.
A humanização do atendimento à saúde proporciona maior assimilação e participação dos envolvidos: paciente, família e equipe multiprofissional, sendo uma política nacional que visa à melhoria das condições de trabalho, para que os profissionais possam oferecer um atendimento de qualidade ${ }^{(11)}$. Essa diretriz tem consonância com uma das atuais tendências da assistência pediátrica, o cuidado atraumáutico, conceituado como um cuidado terapêutico que pressupõe o uso de intervenções apropriadas, como o brinquedo para diminuir ou eliminar o sofrimento físico e psicológico da criança e de sua família no sistema de cuidado à saúde ${ }^{(3)}$.

Vale ressaltar que o uso do brinquedo pelo enfermeiro é recomendado e regulamentado pelo Conselho Federal de Enfermagem, por meio da Resolução n²95/2004 que reza em seu artigo $1^{\circ}$ : “compete ao enfermeiro que atua na área pediátrica, enquanto integrante da equipe multiprofissional de saúde, a utilização da técnica do Brinquedo/Brinquedo Terapêutico, na assistência à criança e família"(12).

Diante do exposto, propusemo-nos a realizar este estudo, que teve como objetivos: preparar a criança préescolar para punção venosa por meio do BTI e conhecer a percepção dos familiares quanto a esse preparo.

\section{MÉTODOS}

Trata-se de um estudo descritivo de natureza qualitativa, devido ao fato dessa abordagem considerar a particularidade do sujeito, permitindo uma melhor compreensão de seu mundo ${ }^{(13-14)}$.

A pesquisa teve início após autorização da instituição onde se deu a coleta de dados, aprovação do Comitê de Ética em Pesquisa da Universidade Federal de São Paulo, (Protocolo $n^{\circ}$ 1925/06) e com a concordância dos familiares que assinaram o Termo de Consentimento Livre e Esclarecido.

O estudo foi realizado na unidade de Pronto Atendimento e Pronto-Socorro Pediátrico de um hospital universitário do Município de São Paulo. Os participantes do estudo foram cinco crianças em idade pré-escolar de três a seis anos e seus familiares. Essas crianças já haviam sido anteriormente submetidas ao procedimento de punção venosa, e estavam acompanhadas por seus familiares, perfazendo um total de dez participantes.

Os dados foram coletados entre os meses de maio e setembro de 2007, extraídos das manifestações da criança ocorridas na sessão de BTI realizada durante o preparo e para punção venosa propriamente dita, e por meio de entrevista com seus familiares realizada após esse preparo, norteada pelas perguntas: "O que a senhora achou da utilização do BTI no preparo do seu filho(a) para punção venosa, comparando as punções anteriores e a atual'?

Para explicar o procedimento e a necessidade da 
punção foi contada à criança uma história similar à sua: coleta de sangue para exames laboratoriais ou para administração de medicamento (ANEXO 1). Para tanto, foram utilizadas duas bonecas de pano de $15 \mathrm{~cm}$ denominadas Duda (boneca-menina) e Nanda (bonecamãe), e os materiais necessários à punção venosa, como: agulhas, seringas, algodão, almotolia com álcool, garrote, frasco de soro, equipo e adesivo hipoalergênico.

As sessões de BTI e as entrevistas foram filmadas, gravadas e transcritas na íntegra, para captar a comunicação verbal e não verbal da criança no preparo e durante a punção, assim como conhecer a percepção dos familiares.

Os dados coletados foram analisados de acordo com os preceitos da Análise de Conteúdo de Bardin, seguindo os passos preconizados: Pré-análise - fase de organização, que compreende o primeiro contato com o material, sendo realizada leitura minuciosa dos dados transcritos, para extrair códigos, como unidades de significado; Análise temática - momento em que ocorre a separação e identificação dos temas em unidades de sentido, agrupando-as por similaridade e diferenças para a composição das sub-categorias; Construção das categorias temáticas - realizada por meio de um processo de comparação, quando as sub-categorias foram reagrupadas para atribuir termo conceitual às categorias temáticas ${ }^{(15)}$.

\section{RESULTADOS}

A análise dos dados permitiu descrever cada um dos momentos vivenciados pela criança durante o preparo e a punção propriamente dita assim como o depoimento dos familiares a respeito do preparo da criança para a punção venosa com o BTI, retratados nas categorias temáticas: Entrando no mundo da punção; Conseguindo dramatizar a punção; Vivendo o terror da punção; Experienciando o término da punção; e Reconhecendo os benefícios do brinquedo. Para garantir o sigilo de suas identidades, as crianças estão identificadas pelas siglas: C1 a C5; seus familiares, mãe e avó identificados como M1, M2, A3, M4 e M5 e as pesquisadoras como P1 e P2.

\section{Entrando no mundo da punção}

A criança entra no mundo da punção desde o momento em que lhe é apresentado o kit de brinquedos e contada a história de uma menina (Duda) que recebe explicação de sua mãe (Nanda) sobre a necessidade de ela ser submetida à punção venosa. Imediatamente, todas as crianças estabeleceram interação com o material e relação de confiança com a pesquisadora, independente de ruídos externos, continuando totalmente envolvidas durante a explicação do procedimento, ouvindo atentamente a bistória, fixando seu olhar e prestando atenção, enquanto seguravam Duda para ser puncionada.

No transcorrer da dramatização, a criança demonstra ter entendido a necessidade da punção ao questionar à pesquisadora qual braço de Duda seria puncionado e acenando positivamente com a cabeç, quando lhe éperguntado se compreendeu o procedimento. Além de compreender o objetivo da punção, a criança associa sua necessidade de tomar soro com o que foi representado na boneca ao gesticular positivamente quando perguntado se iria tomar soro igual Duda.

Apesar de ter entendido o motivo pelo qual Duda precisaria ser submetida à punção venosa, no momento em que a criança é convidada a dramatizar esse procedimento, apresenta comportamento ambíguo. Ela confirma seu desejo, balançando positivamente a cabeça, começa a auxiliar na visualização e localização da veia no braço da Duda, e a procurar a veia, apontando no braco de Duda o local que está vendo a veia boa. Porém, no momento em que é solicitada a sua ajuda para garrotear o braço de Duda, passar algodão com álcool, pegar a veia com seringa e agulha, puxar o êmbolo da seringa, ela se nega a dramatizar a execução da punção propriamente dita, balançando firme a cabeça negativamente.

\section{Conseguindo dramatizar a punção}

Mesmo negando-se inicialmente a realizar punção em Duda, a criança, aos poucos, como que enfrentando a realidade da própria punção, vai criando coragem para puncionar o braço da boneca, passando a manipular objetos reais utilizados na punção, que lhe são disponibilizados para brincar: seringa, jelco; algodão com álcool, garrote, esparadrapo e tubo de ensaio. A seguir incentivada pela pesquisadora, comesa dramatizar o procedimento: garroteia o braço de Duda; passa o algodão com álcool no braço de Duda; retira o escalpe da embalagem e o conecta na seringa; introduzindo o jelco no braço de Duda; puxa o êmbolo da seringa; retira o garrote e a agulha; coloca o curativo no braço de Duda.

Durante a dramatização, a criança foi sendo encorajada pelas mãe e avó, recebendo intervenção positiva, das mesmas no sentido de lhe transmitir segurança e proteção, permanecendo ao seu lado, perguntando se ela limpou direitinho o braço de Duda; pedindo para ter cuidado na hora de espetar a boneca e parabenizando-a pelo sucesso na punção de Duda. Essas atitudes denotam o quanto elas também conseguem se envolver numa brincadeira e, assim, encorajar seus filhos.

No transcorrer de todo esse processo, verificou-se relaxamento da tensão da criança observado tanto pela mudança de sua expressão facial como pelo fato de deixar de lado alguns comportamentos como soltar um pacote de salgadinho que segurava enquanto comia seguidamente ou deixar de mascar um chicle.

Ainda, percebeu-se a criança resgatando o controle da situação durante a brincadeira, pois ela passa de papel passivo para dominador e assume ser dona da mesma, tendo a liberdade de expressar-se. Assim, ela ordena, nega, afirma, cala-se e questiona a pesquisadora sobre a necessidade de realizar o procedimento em Duda, como 
exemplificado a seguir:

\section{Vivendo o terror da punção}

No momento em que a criança é relembrada que será a sua vez de ser puncionada, vive o terror da punção intensamente, tenta se resguardar chorando, questionando sobre a real necessidade desse procedimento nela, pois o rompimento da pele é aterrorizante, chamando pela mãe, ou por outro membro da família, sendo ameaçada e advertida por esta, e recebe consolo quando há sucesso na punção. Os dados evidenciaram como o brinquedo propiciou segurança e possibilitou sua compreensão sobre a punção venosa.

Resguardando-se da punção, a criança tenta entender a situação pela qual terá que passar e questiona a mãe se há realmente necessidade de ser feita nela, a punção que foi realizada em Duda: P1: Fecha a mãozinha para a tia. Isso! C2: É sério? É sério mãe? [...] É sério que ela vai fazer isso?

A punção propriamente dita representada pela picada da agulha, se mostra como um evento aterrorizante para a criança, independente de ela ter compreendido a necessidade da punção. Ela manifesta-o chorando, debatendo-se e gritando: não, não quero! Durante esse momento a maioria das crianças chora veementemente, desde quando se pega em sua mão para procurar a veia, assim como quando se coloca o garrote e se faz a assepsia com o álcool e quando ela grita ai ui ui ao ser puncionada.

Além do choro, outras reações das crianças foram observadas: grita pela mãe, dir que está doendo, que estão entortando seu bracinho. Uma das crianças continuou gritando e dizendo não, mesmo após a retirada da agulha.

O terror aumenta quando não há sucesso na primeira tentativa, intensificando a dor e o sofrimento da criança que, chorando muito, pede para não ser novamente puncionada, pergunta à mãe se tem que furar novamente, dizendo: C5: Eu te amo mamãe! E reforça que não quer: Não quero furar! M5: Não vai mais fura, já passou, ta!

Nessa situação, a criança, como que pedindo socorro, grita evocando outro membro da família, lembrando-se, das pessoas que ela gosta como o irmão e a tia: C2: Ai mamãe en quero irpara o P. (irmão). Eu quero a minha tia. No sentido de proteger a criança, a mãe permanece ao seu lado, abraça-a e a consola, dizendo: M2: Eu também te amo meu amor. É para o seu bem, querida!

Observou-se, no entanto, que quando a criança apresenta muita resistência, os pais demonstram impaciência, assumindo um papel dominante e autoritário, chegando, inclusive, a ameaçar a criança.

M4: O que a mamãe conversou com você? Oh! Deixa eu falar uma coisa pra você: o quê a mamãe conversou com você? Olha pra mim! Ou você quer ficar internado lá no hospital? Você quer injeção no bumbum? Quer injeção no bumbum a gente dá?! [...] Ah, então vai na perna! Pára! Pára agora! [...] Por que você está chorando deste jeito? Pode parar! [...]Chega! Chega! Chega! [...] Não pode ficar puxando o braço. Se você ficar mexendo vou dar o outro braço. Então não mexe! Você vai mexer de novo? [...] Está vendo, você fica mexendo, vai ter que furar de novo porque você mexeu! Vai sim!

\section{Experienciando o término da punção}

Mesmo quando termina a punção, tanto para coletar sangue para exames laboratoriais, como para instalar soro, a criança ainda continua chorando e ao final deste processo ela é confortada pela mãe e tranquilizada pelo profissional. É um momento de alívio para todos, criança, mãe e profissional e estes, imediatamente, comunicam à criança sobre a finitude do procedimento, o êxito da punção e a elogiam pela coragem do enfrentamento.

M2: Acabou! [...] Já vai tirar, já vai tirar. Pronto! Pronto! A lá! Pronto!

P2: Olha vou dar parabéns para você ta! Porque você fez. tudo certinho, você não tirou o braço, fez tudo certinho, e foi muito corajoso, viu! Parabéns!

No caso de ser um menino, quando este apresenta o comportamento esperado pela mãe, como não chorar ou verbalizar que a punção venosa não foi dolorosa, ele é comparado a um homem grande, pois, na nossa sociedade, há o estereótipo do homem não chorar e não demonstrar seus sentimentos.

Ao mesmo tempo em que a mãe tenta consolar a criança, fica evidenciado o quanto é sofrido, estar com seu filho no momento da punção.

C2: Tem que furar de novo mãe?M2: É a última vez! Se ela não conseguir eu não deixo mais! Chega!

\section{Reconhecendo os benefícios do brinquedo}

No transcorrer desse processo, verificou-se relaxamento da tensão da criança observado tanto pela mudança de sua expressão facial como pelo fato de deixar de lado alguns comportamentos como soltar um pacote de salgadinho que segurava enquanto comia seguidamente ou deixar de mascar um chicle.

Percebeu-se, ainda, o resgate do controle da situação pela criança durante a brincadeira, pois ela passou do papel passivo para dominador e assumiu o domínio, tendo a liberdade de expressar-se. Assim, ela ordena, nega, afirma, cala-se e questiona a pesquisadora sobre a necessidade de realizar o procedimento em Duda, como exemplificado a seguir:

\section{C3: Punciona a veia no braço da Duda e dá ordem: Não pode} mexer!!

P1: Quer colber mais?(sangue) C2: Gesticula com a cabeça dizendo que não e pergunta: Ela vai tomar injeção de novo? P1: 


\section{De novo? Será que ela vai precisar? C2: Não!}

Todos os familiares e responsáveis pela criança expressaram o quanto o preparo da criança com o BTI foi bom, importante, benéfico, serviu para ensinar à criança sobre o processo da punção e proporcionou segurança tanto para elas como a eles próprios que chegaram a agradecer por essa intervenção ter sido realizada.

A3: Nossa! Foi ótimo! Ele, graças a Deus, vai receber todas as medicacõos, os medicamentos, numa boa, e isso é muito importante, né?? E seria bom se tivesse uma platéia de criançinha, né! Para assistir, né? Ai se sentiriam bem mais seguros, né? Que elas vem todas muito apavoradas, né!? Então, tudo depende de conversar como é que vai fazer, que é o que vocês estão fazendo. Tá ótimo! [...] $E$ até a gente se sente segura também, né? A gente se sente segura. Eu fico agradecida!

M5: Assim, eu achei legal. [...]. Assim, que é a primeira vez, pra ensinar, assim, pra ensinar que ela teve ninguém, nunca. Desde o comeso do tratamento dela, ensinamento assim não teve não.

\section{DISCUSSÃO}

Neste estudo foi observado que desde o primeiro momento, quando a criança entra em contato com o kit do BTI, ela estabelece interação e relação de confiança com a pesquisadora. Isto ocorre porque, sendo peculiar ao seu mundo, a brincadeira proporciona à criança a possibilidade de compreender o significado das situações fazendo com que em um evento no qual ela é o sujeito passivo, transforme-se em investigador e controlador ativo, adquirindo o domínio da situação utilizando, para tanto a brincadeira e a fantasia ${ }^{(16)}$.

A dramatização e a repetição, no brincar, de uma atividade que determine situação de estresse são imprescindíveis à criança para ela interiorizar uma situação difícil e se fortalecer no sentido de enfrentá-la, dominá-la ou torná-la suportável, conforme é enfatizado por importantes teóricos como Freud, Erikson e Piaget ${ }^{(17)}$.

O domínio da situação ficou evidenciado neste estudo, quando a criança, durante a brincadeira, resgata de alguma forma sua autonomia, negando ou afirmando sua participação na atividade de brincar, quando lhe é solicitado para executar algum procedimento no boneco e questionando à pesquisadora sobre a necessidade da punção.

O desejo de exercer autonomia e compartilhar decisões a respeito dos cuidados a serem realizados com elas foi manifestado por crianças hospitalizadas, que perceberam ter essa demanda atendida quando: foram ouvidas; receberam explicações sobre os procedimentos em linguagem de fácil entendimento e adequada ao seu nível de maturidade; puderam fazer escolhas e tiveram a participação da família no contexto assistencial ${ }^{(18)}$.

A autonomia exercida pela criança, aliada à possibilidade dela manipular o material real que será utilizado na punção são fatores imprescindíveis para auxiliá-la a superar o medo e o sofrimento relativos ao procedimento doloroso ao qual deverá submeter-se, pois, como enfoca a literatura, há ampla evidência de que as crianças ficam mais bem preparadas para procedimentos dolorosos, quando lhes é permitido manusear previamente o material que será utilizado ${ }^{(4)}$, conforme propicia o BTI.

Estudo realizado com crianças pré-escolares revelou que o brinquedo terapêutico ameniza a sensação de elas se perceberem pequenas em decorrência da hospitalização, especialmente dos inúmeros procedimentos, que para elas, são aterrorizantes ${ }^{(19)}$.

O terror se instala no momento da realização da punção venosa quando há o rompimento da pele pela agulha, uma vez que, na idade pré-escolar, apesar dos progressos do desenvolvimento da imagem corporal, a criança tem noção pouco definida de limites corporais e de sua anatomia, e se atemoriza quando há o rompimento da pele pela agulha, temendo que o conteúdo de seu corpo escape de seu interior pelo orifício ${ }^{(20-21)}$.

No entanto, as crianças sentem-se mais seguras e compreendem a necessidade da punção venosa quando a dramatizam na boneca, visto que, quando lhes é solicitado o braço para puncionar, elas o oferecem sem resistência, após terem sido preparadas com o BTI, revelando o valor dessa intervenção no sentido de favorecer a compreensão da criança sobre o procedimento, conforme tem sido apontado pela literatura ${ }^{(2,4)}$. Como explica Piaget, a repetição de uma situação difícil e dolorosa, na brincadeira, não tem o sentido de preservar a dor, mas sim de tornála suportável pela assimilação do ego da $\operatorname{criança~}^{(17)}$.

A importância, para a criança, da presença, do apoio e da proteção dos pais durante o procedimento, verificado neste estudo tem consonância com achados da literatura ${ }^{(19,22)}$. Vale ressaltar, que o fato das mães se tornarem impacientes, frente aos comportamentos de choro e negação da criança, relacionados à punção, pode ser atribuído à tensão gerada pela convivência com o sofrimento do filho e a impotência de não conseguir impedi-lo.

Assim, embora a mãe seja reconhecidamente uma fonte de segurança para a criança, ela também precisa ser cuidada, pois, frente à necessidade de um procedimento ela tem que lidar tanto com o sofrimento da criança, como com o seu próprio sofrimento ${ }^{(5,19,23)}$. Para tanto, é necessário uma mudança do enfoque da assistência de enfermagem tecnicista e centrado na doença, para um enfoque centrada na criança e na família ${ }^{(19,24)}$.

Uma pesquisa revela, também, que embora os pais aprovem o preparo para a coleta de sangue com BTI, eles ficam decepcionados e têm dificuldade para compreender porque os filhos continuam apresentando 
as manifestações de tensão anteriormente descritas, uma vez que receberam explicação e puderam brincar e manusear o material a ser utilizado ${ }^{(7)}$.

Neste sentido, enfatizamos que, embora o preparo da criança com o brinquedo ofereça condições para que ela compreenda a necessidade e a realização da punção e expresse simbolicamente suas emoções, ela pode não mudar imediatamente seu comportamento. Assim sendo, nunca se deve esperar que a criança não reaja ou não chore, durante o procedimento, e isto deve ser compreendido pelos profissionais e explicado aos pais. Reiteramos que, no preparo com o BTI, a criança deve ser informada que poderá chorar e expressar seus sentimentos de medo e desagrado(4).

\section{CONSIDERAÇÕES FINAIS}

Este estudo propiciou a compreensão da importância da utilização do BTI no preparo para a punção como instrumento essencial à assistência de enfermagem, no

\section{REFERÊNCIAS}

1. Bowlby J. Cuidados maternos e saúde mental. São Paulo: Martins Fontes; 1981.

2. Martins MR, Ribeiro CA, Borba RIH, Silva CV. Protocolo de preparo da criança pré-escolar para punção venosa, com utilização do brinquedo terapêutico. Rev Latinoam Enferm. 2001;9(2):76-85.

3. Hockenberry MJ, Wilson D, Winkelstein ML. Wong fundamentos de enfermagem pediátrica. 7a. ed. Rio de Janeiro: Elsevier; 2006.

4. Ribeiro CA, Borba RIH. Preparo da criança e do adolescente para procedimentos hospitalares. In: Almeida FA, Sabatés AL, organizadoras. Enfermagem pediátrica: a criança, o adolescente e sua família no hospital. Barueri: Manole; 2008. p.109-23.

5. Pinto JP, Fernandes RAQ, Teixeira MB. A mãe e a punção venosa do filho hospitalizado: uma visão fenomenológica. Rev Paul Enferm. 2001;20(2):12-9.

6. Oliveira DE. Punção venosa da criança: uma vivência de sofrimento para a família [Monografia]. São Paulo: Departamento de Enfermagem, Universidade Federal de São Paulo; 2003.

7. Conceição CM, Ribeiro CA, Borba RIH. Brinquedo terapêutico no preparo da criança para coleta de sangue: significado para os pais. [Trabalho de conclusão de Curso]. São Paulo: Departamento de Enfermagem, Universidade Federal de São Paulo; 2008.

8. Santos LMCN, Borba RIH, Sabatés AL. A importância do preparo da criança pré-escolar para a injeção intramuscular com o uso do brinquedo. Acta Paul Enferm. 2000;13(2):528 .

9. Ribeiro PJ, Sabatés AL, Ribeiro CA. Utilização do brinquedo terapêutico, como um instrumento de intervenção de enfermagem, no preparo de crianças submetidas à coleta de sangue. Rev Esc Enferm USP. 2001;35(4):420-8.

10. Kiche MT, Almeida FA. Brinquedo terapêutico: estratégia de alívio da dor e tensão durante o curativo cirúrgico em crianças. Acta Paul Enferm. 2009;22(2):125-30.

11. Políticas de Humanização do SUS - PNH. [Internet] 2004. [Citado 2009 Jun 30]. Disponível em: http:// sentido de permitir a construção de um cuidado humanizado no Pronto Socorro Infantil. Ressaltamos que, para a modificação do atual cenário de atendimento no serviço de emergência à criança e família, é necessária maior valorização e crença dessa prática pela equipe de enfermagem.

Nesse sentido, esperamos que este estudo contribua para que a equipe multiprofissional desses serviços, em especial a de enfermagem, sejam motivada a usá-lo com vistas à prestação de cuidados que transcendam o saber biologicista, considerando, também, as necessidades emocionais e sociais da criança e de sua família, de forma que todos os envolvidos neste processo sejam beneficiados.

\section{AGRADECIMENTO}

Agradecemos à enfermeira Giovana Soares Bortolote, membro do GEBrinq, pelo treinamento e acompanhamento das alunas durante a realização das sessões de BTI.

www.saude.sc.gov.br/Eventos/Humaniza_SUS/atas/ A T A \% 20 D A \% 20 R E U N I $\%$ C 3\% 83 O \% $20 \mathrm{DO} \% 20 \mathrm{COMIT} \% \mathrm{C} 3 \% 8 \mathrm{~A} \% 20 \mathrm{DE} \% 20 \mathrm{HUMANIZA}$ $\%$ C3\%87\%C3\%83O\%20\%2001-09-2004.doc

12. Brasil. Conselho Federal de Enfermagem - COFEN. Resolução COFEN - 295/2004, de 24 de outubro de 2004. Dispõe sobre a utilização da técnica do brinquedo/Brinquedo Terapêutico pelo enfermeiro na assistência à criança. Rio de Janeiro: COFEN; 2004. [Internet]. [Citado 2009 Jun 15]. Disponível em: http://www.portalcofen.gov.br/2007/ materias.asp?ArticleID=7123\&sectionID $=34$

13. Matheus MCC, Fustinoni SM. Os fundamentos da pesquisa qualitativa. In: Matheus MCC, Fustinoni SM. Pesquisa qualitativa em enfermagem. São Paulo: Livraria Médica Paulista; 2006. p.17-22.

14. Minayo MCS. O desafio do conhecimento: pesquisa qualitativa em saúde. 11a. ed. São Paulo: Hucitec; 2008.

15. Bardin L. Análise de conteúdo. 3a ed. Lisboa: Edições 70; 2004.

16. Treeza EMC. Função dos jogos e brinquedos na vida da criança. J Pediatr (Rio J). 1977;42(6):55-8.

17. Ribeiro CA, Maia EB, Sabatés AL, Borba RIH, Rezende MA, Almeida FA. O brinquedo e a assistência de enfermagem à criança. Enferm Atual. 2002;25:6-17.

18. Ueno KH, Pettengill MAM. Autonomia da criança hospitalizada: este direito é respeitado? Rev Soc Bras Enferm Ped. 2006;6(1):9-16.

19. Ribeiro CA, Angelo M. O significado da hospitalização para a criança pré-escolar: um modelo teórico. Rev Esc Enferm USP. 2005;39(4):391-400.

20. Brazelton TB. Momentos decisivos do desenvolvimento infantil. São Paulo: Martins Fontes; 1994.

21. Silva LR. A utilização do brinquedo terapêutico na prescrição da assistência de enfermagem pediátrica. Revisão de Literatura. Texto \& Contexto Enferm. 1998;7(3):96-105.

22. Schutlz LF. A família vivenciando a doença e a hospitalização da criança: protegendo o filho do mundo e não o mundo do filho. [tese]. Guarulhos: Universidade de Guarulhos; 2007. 
23. Oliveira I, Angelo M. Vivenciando com o filho uma passagem difícil e reveladora: a experiência da mãe acompanhante. Rev Esc Enferm USP. 2000;34(2):202-8.

24. Borba RIH, Pettengill MAM, Ribeiro CA. A enfermagem e a família da criança hospitalizada In: Almeida FA, Sabatés AL, organizadoras. Enfermagem pediátrica: a criança, o adolescente e sua família no hospital. Barueri: Manole; 2008. p. 99-108.

\section{Anexo 1}

\section{A história de Duda no hospiatal}

Olá, (nome da criança). Vamos explicar para você o que viemos fazer, contando a história da Duda, uma menina de três anos e de sua mãe Nanda.

Certa manhã Duda acordou triste, desanimada, sem vontade de comer e brincar, com dor e febre. Então, Nanda estranhou o comportamento de sua filha, pois Duda é uma criança bem esperta. Assim, decidiu levá-la ao hospital.

Já no hospital, Duda foi examinada pelo médico, o qual disse que ela precisaria ficar internada para colher sangue (ou tomar remédio na veia para melhorar mais rápido). Após a consulta médica, Nanda foi explicar para Duda como ela iria colher o sangue (ou receberia o remédio na veia):

- Duda, a enfermeira vai pedir para você esticar o braço, apertá-lo um pouco com este garrote que é uma borracha para ver a sua veia. Depois, vai limpar a pele com algodão e álcool. Não mexa com o seu braço para pegar a veia. Se não conseguir pegar sua veia na primeira picada, vai precisar furar de novo. Vai doer na hora da picada, mas vai passar assim que pegar a veia.

Então, a enfermeira, vai tirar o sangue e colocar nesse tubo para fazer o exame e tirar o garrote e colocar um esparadrapo no local da picada. (ou vai tirar o garrote de seu braço, pegar este equipo, conectar a agulha e depois abrir a torneirinha para o remédio entrar para seu corpo, prender a agulha com um esparadrapo e colocar uma tala em baixo de seu braço para você não mexer, prendendo com uma atadura e outro esparadrapo para que a agulha não saia da veia.

A mamãe vai ficar com você o tempo todo ao seu lado. Pode chorar se quiser, só não pode mexer o seu braço. 